\title{
Perceived Parenting Style, Self-Compassion, Resiliency and Bullying Behavior among Early Adolescents
}

\author{
Yosr Mohamed Elmasri ${ }^{1}$, Josephin A. Lawend ${ }^{2}$,Warda Elshahat Hamed ${ }^{3}$ \\ ${ }^{1}$ Assistant professor of psychiatric and mental health nursing, Mansoura University \\ ${ }^{2}$ Assistant professor of pediatric nursing, Mansoura University. \\ ${ }^{3}$ Lecturer of psychiatric and mental health nursing, Mansoura University.
}

\begin{abstract}
:
Background: Children are first educated in their families, and by adapting different parenting styles, Parents consciously and in most cases unconsciously teach their children important behavioral and psycological doctrines, Aim of the study: this study was conducted to explore the perceiption of parenting style, self-compassion, resiliency and mitigating bullying behavior among early adolescents. Subjects and Methods: Research design: Cross-sectional exploratory design was used to achieve the present study aims. Setting: This study was conducted at Al-Azhar preparatory institutes (Darjeel, Kafr Hijazi and Kafr Al-Galatia) Menofya Governorate.Subjects: A convenient sample of 306 students was selected from AlAzhar preparatory institutes. Tools of data collection: Parenting Style Scale, self compassion, psychological resilience and bullying behavior. Results: The study results indicated that, there was a highly positive correlation between the overall parenting style of the father and the total student's self-compassion and total bullying. While there was no statistcal correlation with the student's psychological resilience. On the other hand, there was no statistical correlation between the overall parenting style of the mother and the total student selfcompassion, psychological resilience and totale bullying behaviors. Conclusion: It was concluded that the results of the study show a lower level of parenting despite the fact that early adolescents have a good sense of self-compassion, excellent psychological resilience and low levels of bullying.Recommendations: It is recommended that application of the study on a larger and more diverse samples of adolescents, and it would be advantageous to collect data directly from parents in regard to their parenting style.
\end{abstract}

Key words: Parenting style, Self-compassion, Psychological resilience, Bullying behaviors, Early adolescents 


\section{Introduction:}

A parenting style is a psychological concept that reflects traditional techniques that parents use when rearing their child ${ }^{(\mathbf{1})}$. Parenting is about human growth, more precisely the parenting style laid the groundwork for exploring the form of parenting conducive to the effective socialization and development of children and adolescents ${ }^{(2)}$. Adolescence is a transition period from childhood to adulthood, where adolescents experience rapid and significant physiological, social, psychological, spiritual, and emotional growth and development during this time. The quality of family relations with adolescence plays an important role in this period .The development of teenagers is influenced by many factors such as race, culture, and parenting style. Adolescent's willingness to follow appropriate behavioral expectations is seen as a successful internalization of parental principles, guided not only by expectation of external consequences but also by intrinsic or internal factors ${ }^{(3)}$.

Parenting style has a positive relationship with confident on the adolescents, if the parents give verbal forcefulness to their kids, it will be effected to the children's self-confidence. As parents, it is essential to select the parenting style that can improve the aspects of adolescent and build their positive behaviour. Within this conceptualization, both scientists agree that there are at least three broad dimensions of parenting, the first dimension being parental support, often linked to the affective nature of the relationship between parents and children. It is demonstrated by engagement, acceptance, emotional availability, warmth and responsivenes ${ }^{(4)}$. The second element is behavioral management with reasonable standards of maturing actions along with consistent limit sitting. The third dimension is supporting autonomy which encourages children to actively discover, explore and communicate their goals and perspectives $^{(\mathbf{5})}$.

The permissive parenting style is a liberal parenting style in which adults make no demands, empower their children to communicate their feelings and never use coercion to take control of their actions. The parents in this style cause to their children speech delays, because of busyness, lack of stimulation and interaction $^{(\mathbf{6})}$. Parents characterized by this style tend not to allow their children to follow mature behaviour, but rather to promote independence. Authoritative parenting consists of a set of parenting 
characteristics that include high expectations, moral support, loving, awareness of the expressions of the children's needs, promotion of bidirectional contact and effective implementation of whatever laws are laid down ${ }^{(7)}$.

Authoritarian style of parenting is a highly authoritarian style of parenting in which adults seek to enforce multiple laws, require strict compliance, and sometimes rely on physical discipline to comply. These parents seem not to be sensitive but demanding ${ }^{(\mathbf{1})}$. This style is strongly linked to academic achievement of the students at the school or any activity in school, autonomy, prosocial activity and the internalization of values by children. It is recommended for parents for nurturing their children in modern cities ${ }^{(\mathbf{8})}$.

Adolescents who considered their parents to be competent found that they had higher rates of intellectual competence and lower levels of psychological and behavioral impairment relative to adolescents who viewed their parents to be incompetent. Nonetheless, students who believe they have authoritarian parents do well with obedience and compliance with adult expectations show fairly low self. Adolescents of parents who are permissive / indulgent have a high self-confidence but often have more issues of drug use and abuse within and outside schoolc ${ }^{(9)}$. Authoritative parenting tends to be related to adjustment of the classroom and academic success for children and little externalizing behavioral problems compared to authoritarian and permissive parenting. More broadly, authoritative parenting has been linked to higher rates of self-regulation among adolescents than permissive and authoritarian parenting ${ }^{(\mathbf{8}}$. In addition, it has also been shown that authoritative parenting facilitates stable relationships between children and their caregivers and leads to a greater sense of autonomyc $^{(\mathbf{1})}$.

With regard to the various forms of parenting styles, multiple meta-analyzes have concluded that authoritarian and incompetent parenting is correlated with the prevalence of internalizing symptoms in adolescents possibly due to the lack of acceptance / involvement that characterizes these Parenting styles. As far as strict parenting is concerned, this has been correlated with less internalizing symptoms and greater psychological development in children and adolescents in general $\mathbf{c}^{(10)}$.

Generally, adolescents raised by authoritarian parents appear to have better 
psychosocial skills and have greater mental well-being than the offspring of nonauthoritative parents. For example, it was found that students who are living in an authoritative home reported greater confidence, persistence and academic success compared to their counterparts. A positive relationship between parent and child is one of the most significant determinants of a healthy cognitive, emotional and social growth and plays a key role in the development of selfconception and self-worth ${ }^{(\mathbf{1 1})}$.

Numerous studies have shown that parenting styles are associated with various risk behaviors and personality aspects, particularly when parenting styles such as the Authoritarian or Rejecting-Neglecting styles are very "adverse". For example, in adolescents, higher substance use, lower self-esteem and lower social competence are associated with authoritarian parenting compared to Authoritative parenting. We also know that adolescents with authoritative parents have a significantly higher self-esteem, increased self-control and increased resistance to peer influence, resulting in lower use of substances and violence-related behaviors than peers whose parents are defined as neglecting ${ }^{(\mathbf{1 1}) .}$
The symbolic theory of interactionism ties parenting practices to concern for oneself. The theory says a person is a result of socialization, and sees himself as a reflection of how others treat them ${ }^{(\mathbf{1 2})}$. But parental behaviors and beliefs may be internalized and influenced an individual's level of self-compassion. Higher levels of self-compassion are associated with higher levels of careful parenting, which in turn is associated with higher levels of authoritative parenting and lower levels of authoritarian and permissive styles of parenting ${ }^{(13)}$.

Self-compassion is often rooted in early caregiving experiences and our attachment system is shaped by our parenting style experience. Our self-compassion will therefore vary as a function of our early experience of attachment. If we have encountered neglect or any sort of physical or emotional violence, we may have developed emotional memories that associate the experience of needing and/or receiving treatment with negative emotions of guilt, rage, isolation, fear or vulnerability. Our capacity to experience associated emotions like affection, sympathy, longing and sorrow for others and ourselves can be seriously compromised $^{(\mathbf{1 4})}$. 
Resilience has been described in a number of ways, including the ability to bounce back or recover from stress, adapt to challenging situations, not become ill despite significant adversity and work above the average despite stress or adversity ${ }^{(15)}$. Resilience helps one to function while experiencing difficulties which damage the person. Those with high resilience are rich in mental capital, such as life satisfaction, confidence and a relaxed mind. They can invoke psychological tools to deal with problems at any time and escape hardship when faced with a challenging atmosphere ${ }^{(\mathbf{1 6})}$.

Resilient adolescents in classrooms have been identified as functioning and playing well and keeping high expectations, have also been characterized by buildings such as locus of control, self-esteem, selfefficacy and autonomy, all of which work together to prevent harassment behaviors associated with learned helplessness ${ }^{(17)}$.

Bullying was a universal problem of conduct that occurs in schools. It has become a global issue needing the involvement of all actors of the education sector. Studies have found that bullying is a daily issue of conduct that occurs in virtually every school ${ }^{(18)}$. Bullying is not related to a particular culture but it is a worldwide phenomenon, it is a distinct type of violence marked by persistent and systematic power abuse. It happens when one or more students try physical, verbal or emotional control, bullying, or even alienation over another student. Scientists consider that any act which aims to harm another person without cause is called bullying $^{(19)}$.

Nevertheless, most research on the impact of parents on bullying has concentrated on strict, punitive parenting styles in which parents effectively model their children's bullying behaviour ${ }^{(20)}$. Findings based on other areas of psychological functioning also show that adverse parenting individuals are more likely to exhibit unsafe attachment behaviors and have a significantly higher risk of depressive or anxious behavior ${ }^{(21)}$.

A research on the prevalence of school bullying in Egypt identified violent characteristics of 35 percent and violent behavior of 11.7 per cent among preparatory school students. Another research carried out in Egypt found that $51 \%$ of boys and $20 \%$ of girls in preparatory and secondary schools had perpetrated violent attacks in schools

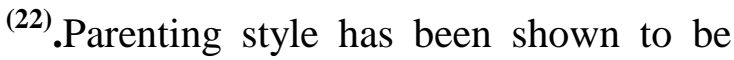
closely related to various characteristics of parent-adolescent relationships (e.g., stability, conflict) and is strongly linked to 
self-compassion, psychological resilience, and reducing bullying among their children. However, comparatively less attention is paid to how adolescence view the parenting style and how these variables interact with each other, with no systematic assessment. It has therefore become important to conduct this study to investigate perceived parenting style, selfcompassion, resiliency and mitigating bullying behavior among early adolescents.

\section{Aim of the study:}

This study aimed to explore the percieption parenting style, self-compassion, resiliency and mitigating bullying behavior among early adolescents.

\section{Research Questions:}

1. Is the parenting style associated with the self-compassion, psychological resilience and bullying behaviors of the early adolescent student?

2. To what extent type of pertaning effect ofself-compassion, resiliency and bullying behavior among early adolescents?

\section{Subjects and Methods:}

Research Design: this study utilized crosssectional exploratory design.

\section{Research Setting:}

Al-Azhar preparatory institutes for males located in the alshuhada' center (Darjeel, Kafr Hijazi and Kafr Al-Galatia) Menofya
Governorate. All of them are affiliated to Al-Azhar Al-Sharif.

\section{Subjects:}

\section{The sample size:}

Based on the data from literature, the estimation of the sample size is presented from a given population (1500). This table was developed on the basis of a formula established by the National Education Association to determine the sample size (Arkin, 1960) ${ }^{(23)}$.

$$
\begin{gathered}
\mathrm{n}=\quad p(1-p) \\
(\mathrm{SE} \div \mathrm{t})+[p(1-p) \div \mathrm{N}]
\end{gathered}
$$

The sample size of the students was determined according to formula in which the minimum sample size needed for the adolescents' students was 306 students selected from three preparatory institutions.The total number of preparatory students was 712 , the level of confidence was stipulated at 95 percent, the "P" response rate was 50 percent, and the "SE" (standard of error) was 0.05 , so the calculated sample was 306 participants from selected institutions.

\section{Tools of data collection:}

Data was collected using the following tools:

\section{Socio-demographic characteristics:} age, level of education and occupation of the parents; sibling arrangement, dwelling, size of the family and residence. 


\section{Parenting Style Scale:}

This tool was developed and adopted by by abdelaziz (1987) (24) to measure parenting style. The scale contains 40 items about parenting style as perceived by kinderen, grouped into 4 subscales, namely: first; Dependency- independency: (the high score indicates independence where parents allow a kind of independence is represented by free job and friends' selection, choice of books to read, freedom to express an opinion and spend free time, whereas the low score indicates dependence). Second; Oscillation - consistency: (the high score indicates consistency, which means the reliability of the parents in utilizing forms of compensation and punishment, while the low score shows oscillation, which means instability). Third; Rejection acceptance:(the high score indicates approval; it is the children's feelings of love, affection and emotional warmth in different daily circumstances, while the low score indicates rejection as well as lack of acceptance and a sense that son's behavior and thoughts are ridiculous. Fourth; Discrimination - equality: (A high score indicates equality among all children, while a low score indicates a discrimination among children based on position, age, or any other reason).
Scoring system: The scale was modified for the current study into 3-point likert scale for both father and mother with response options of Yes (2), No (0) and I don't know (0). The scores for each subscale are collected to get the total score for the sub-scale. The sub-scale scores are collected to get the overall scale score. The sub-scale score ranges from 0-20 while the overall scale score ranges from 0-80.The high total score refers to the tendency of parents (father and mother) to general equality in parenting style, while the low total score refers to the tendency of parents to be out of touch with socializing methods.

\section{3- Neffe's Self- Compassion Scale:}

It was firstly designed and adopted by Raes, Pommier, Neff, and Gucht, (2010) ${ }^{(25)}$ used to measure. It consists of 12 items under six subscales which are:Selfkindness(e.g. I try to be loving toward myself when I'm feeling emotional pain), Self-judgement(e.g., I'm disapproving and judgmental about my own flaws and inadequacies), Common humanity(e.g.,I try to see my failings as part of the human condition), Isolation items (e.g., When I think about my inadequacies it tends to make me feel more separate and cut off from the rest of the world), Mindfulness(e.g.,When something painful 
happens I try to take a balanced view of the situation), Over- identified(e.g., BWhen I'm feeling down I tend to obsess and fixate on everything that's wrong),

Scoring system: The student rate every part of items on a five (5) point scale of 1(never), 2(rarely), 3(sometimes), 4(often), and 5(always). Thiswas for positive items as self -kindness, common humanity and mindfulness. For the negative items as selfjudgement, isolation and over identified the score is reversed, it will be, 5(never), 4(rarely), 3(some times), 2(often), and 1(always). The total score for 12 items is 60. The higher score is 60 and the lower is 12. The higher the score the higher self compassion the teacher has and the lower score the lower self -compassion the teacher has.

\section{4- Violence / Bullying Scale:}

The Scale of violence / bullying among middle school student is created and adopted by Jamal Al-Din (2008) ${ }^{(26)}$, The scale consists of 36 items with Yes or No questions divided equally into two parts; Violence / verbal bullying that has 18 items indicating verbal bullying, Violence /physical bullying that has 18 items indicating physical bullying. The tool has been established to measure the bullying among preparatory school students (bully).

\section{Scoring System:}

The answer with yes takes 1 mark or No takes zero only. The total marks 36. The higher score the higher bullying behaviour and the lower score indicates lower bullying behaviour.

\section{5- Resiliency scale:}

The scale was prepared by Jew,Green and Kroger, (1999) (27). It is the first instrument or scale prepared and designed Arably in Egypt and the Arab world to measure resilience, and the scale consists of four dimensions are as follows; social support, personal efficiency/capabilities, religious and value structure. The scale elements quantify resilience, and there are three alternatives in front of each sentence that are "apply to the whole," "apply to sometimes," and "do not apply at all."

Scoring system: The subject selects one of the three previous alternatives, so that the sentences are corrected in the event of positive statements, the answer: apply to completely $=3$ apply to sometimes $=2$; do not apply at all $=1$; while in the case of negative expressions, the grades are reversed apply to completely $=1$, apply to sometimes $=2$, do not apply at all $=3$. The scale consists of 45 elements with total score consists of 135 elements that quantify resilience, a high score on a scale 
indicates a high degree of resilience, while a low score indicates a low degree of resilience level.

\section{Ethical consideration:}

Approval from the research ethical committee of the faculty of nursing, Menofya University was attained. An official letter from was obtained from the directors of schools after an explaining of the aim, methods, duration and the benefits of the study. Written informed consent was obtained from every student included in the study afterexplaining the importance and the aim of the study. Confidentiality the collected data was assured. Anonymity of the study participants was assured. Participants' voluntary participation and their right to withdraw from the study at any time were emphasized.

\section{Pilot study:}

To check the clarity and simplicity of questions, a pilot study was carried out on 10 percent of the subjects (30) students. Minimal changes to the tools were made. Students included in the pilot study have been excluded from subjects of the study.

\section{Validity and Reliability}

The 5 data collection tools will be tested for their content validity by 5 experts in the fields of pediatric and psychaitric nursing. Reliability checks were also carried out using the Alpha Cronbach test: Parenting scale $\alpha=77$, self-compassion Scale $\alpha=$ 0.90 , and scale 0.80 for violence/ bullying scale.With regard to the scale of resilience, reliability coefficients for scale measurements ranged from 0.74 to 0.86 , which indicates the scale's reliability.

\section{Field Work:}

Preparation of data collection methods was performed over a period of approximately three months from November 2019 to the end of January 2020. Official approvals were obtained from the Dean of the Faculty of Nursing, Menofyia University and the heads of the schools where the research was carried out. Collection of data took place for two days a week (Sundays and Wednesdays) from 10.00 a.m. to 12.00 $\mathrm{pm}$. Through out the beginning of the day the questionnaires were distributed to each class and ask them to fill in the questionnaires in break time. Each participant was asked to fill out the questionnaire and return it to the researcher.

\section{Statistical Design:}

Computerized data entry and statistical analyses were fulfilled using the statistical package for social sciences software (SPSS) version 21. Data were presented using descriptive statistics in the form of frequencies, percentages, means and standard deviations for quantitative 
variables. Correlation between variables was evaluated using Pearson's correlation coefficient. Significance was adopted at $\mathrm{P}$ $\leq 0.05$ for interpretation of the results of tests of significance.

\section{Results:}

Table (1) revealed the majority of adolescents

$(85.9 \%)$ over 12 years of age with average $\pm \mathrm{SD}=13.7 \pm 1.4$, though nearly half of them $(46.1 \%)$ were the oldest in their families and the majority (95.1\%) were from rural areas. Moreover, more than three quarters $(77.5 \%)$ of their families have 4 to 7 members and most $(98.4 \%)$ live with their father and mother.

Table (2) represented that about three quarters of mothers $(74.8 \%)$ were from 28 to less than 39 compared to near one third of the fathers in same age with mean age for mothers and fathers $(36.7 \pm 4.7 \&$ $41.3 \pm 6.5)$ respectively. Moreover, near two thirds of mothers $(61.8 \%)$ have secondary education compared to more than half of fathers $(56.9 \%)$ and the majority of fathers were working compared to more than one third of mothers (39.9\%).

Table (3) presented that adolescnts perceived that more than of their fathers (54.6\%) compared to less than two thirds of mothers $(64.1 \%)$ allow their adolescnts to be independent with a mean score for them

$(4.64 \pm 1.92 \& 5.09 \pm 1.84)$, respectively). Less than half of fathers $(45.4 \%)$ were consistent and stable in dealing with their adolescnts compared to $40.5 \%$ of mothers and nearly two thirds of them accepted their behaviors $(61.1 \%)$. In addition, about $67.3 \%$ of fathers and less than three quarters of the mothers $(70.3 \%)$ discriminated equally between their adolescnts $(3.67 \pm 1.97 \& 3.67 \pm 1.98)$.More than two thirds of the fathers $(67.3 \%)$ and $62.4 \%$ of the mothers have lower level of parenting style.

Table (4)clarified that more than three quarters of the studied students $(77.1 \%)$ have higher self-compassion with total mean score $(34.35 \pm 6.89)$. Nearly three quarters of them $(72.5 \%)$ have overall lower violence/ bullying with total mean score $(11.96 \pm 7.15)$. Almost nearly to all of them have higher degree of psychological resilience $(99.7 \%)$ with a mean total score (94.25 \pm 11.36$)$.

Table (5) represented that is highly positive correlation between total father parenting style and total self-compassion with total bullying with no correlation between it and and total psychological resilience. However no correlation exists between total mother parenting style and the study variables. 
Table (6) revealed that mother's total parenting style was highly and positively correlated with the sibiling arrangement and family size, and father's total parenting style was highly and positively correlated with the family size. There was a highly positive association between total selfcompassion and the age of the student, sibiling structure, and size of the family. There was also a strongly positive association between total psychological resilience and the age of the student. While total abuse was strongly negatively associated with the age, family size and residence of the student.

Table (7). Showed that adolescent's selfcompassion $(\mathrm{t}=4.758, \quad \mathrm{~B}=0.190, \quad \mathrm{P}$ $=0.000)$, psychological resilience $(\mathrm{t}=-$ $0.272, \quad \mathrm{~B}=-0.011, \mathrm{P}=0.786$ ), bullying behaviour $(\mathrm{t}=5.642, \mathrm{~B}=0.231, \mathrm{P}=0.000)$, and Mother parenting style $(\mathrm{t}=18.65, \mathrm{~B}=$ $0.708, \quad \mathrm{P}=0.000)$ can predict father parenting style.

Table (8) illustrated that self-compassion ( $\mathrm{t}=-2.43, \quad \mathrm{~B}=-0.103, \quad \mathrm{P}=0.015)$, psychological resilience $(\mathrm{t}=1.28, \mathrm{~B}=0.052$, $\mathrm{P}=0.201)$, bullying behaviors $(\mathrm{t}=-3.881, \mathrm{~B}$ $=-0.169, \mathrm{P}=0.000$ ), and father parenting style $(\mathrm{t}=18.652, \mathrm{~B}=0.757, \mathrm{P}=0.000)$ can predict Mother parenting style. 
Table (1): Frequency distribution of adolescents' socio-demographic characteristics.

$($ no. $=306)$

\begin{tabular}{|c|c|c|}
\hline Students characteristics & No. & $\%$ \\
\hline \multirow{3}{*}{$\begin{array}{c}\text { Agein Years } \\
<12 \mathrm{ys} \\
\geq 12 \mathrm{ys}\end{array}$} & 43 & 14.1 \\
\hline & 263 & 85.9 \\
\hline & \multicolumn{2}{|c|}{ Mean \pm SD $=13.7 \pm 1.4$} \\
\hline \multirow{3}{*}{$\begin{array}{l}\text { Sibling arrangement } \\
\text { - The oldest } \\
\text { - The youngest } \\
\text { - The middle between his brothers }\end{array}$} & 141 & 46.1 \\
\hline & 77 & 25.2 \\
\hline & 88 & 28.8 \\
\hline \multirow{3}{*}{$\begin{array}{l}\text { - Rural } \\
\text { - Urban }\end{array}$} & & \\
\hline & & \\
\hline & 15 & 4.9 \\
\hline \multicolumn{3}{|l|}{ Family size } \\
\hline 3 members & 55 & 18 \\
\hline 4-7 members & 237 & 77.5 \\
\hline$>7$ members & 14 & 4.6 \\
\hline \multicolumn{3}{|l|}{ Dwelling } \\
\hline - Lives with father and mother & 301 & 98.4 \\
\hline - Lives with the mother only & 3 & 1.0 \\
\hline - Lives with the father only & 2 & 0.7 \\
\hline - Neither live with the mother nor the father & 0 & 0 \\
\hline
\end{tabular}


Table (2): Distribution of the socio-demographic characteristics of the student's parents. (no.=306)

\begin{tabular}{|c|c|c|c|c|}
\hline \multirow{2}{*}{$\begin{array}{l}\text { socio-demographic characteristics } \\
\text { of the student's parents }\end{array}$} & \multicolumn{2}{|c|}{ Mothers } & \multicolumn{2}{|c|}{ Fathers } \\
\hline & No. & $\%$ & No. & $\%$ \\
\hline \multicolumn{5}{|l|}{ Age } \\
\hline $28-<39$ & 229 & 74.8 & 95 & 31 \\
\hline $39-<50$ & 74 & 24.2 & 183 & 59.8 \\
\hline$\geq 50$ & 3 & 1.0 & 28 & 9.2 \\
\hline Mean \pm SD & \multicolumn{2}{|c|}{$36.7 \pm 4.7$} & \multicolumn{2}{|c|}{$41.3 \pm 6.5$} \\
\hline \multicolumn{5}{|l|}{ Education } \\
\hline Illiterate & 2 & 0.7 & 2 & 0.7 \\
\hline Read and write & 38 & 12.4 & 32 & 10.5 \\
\hline Secondary & 189 & 61.8 & 174 & 56.9 \\
\hline University & 55 & 18 & 64 & 20.9 \\
\hline Higher studies & 22 & 7.2 & 34 & 11.1 \\
\hline \multicolumn{5}{|l|}{ Occupation } \\
\hline Working & 122 & 39.9 & 301 & 98.4 \\
\hline Not working & 184 & 60.1 & 5 & 1.6 \\
\hline
\end{tabular}


Table (3): Frequency distribution of adolesents' perception to their parenting style (no= 306)

\begin{tabular}{|c|c|c|c|c|}
\hline \multirow{2}{*}{ The parenting style subscales } & \multicolumn{2}{|c|}{ Father } & \multicolumn{2}{|c|}{ Mother } \\
\hline & No. & $\%$ & No. & $\%$ \\
\hline \multicolumn{5}{|l|}{ Dependency- independency } \\
\hline Dependency & 139 & 45.4 & 110 & 35.9 \\
\hline Independency & 167 & 54.6 & 196 & 64.1 \\
\hline Mean \pm SD & \multicolumn{2}{|c|}{$4.64 \pm 1.92$} & \multicolumn{2}{|c|}{$5.09 \pm 1.84$} \\
\hline \multicolumn{5}{|l|}{ Oscillation - consistency } \\
\hline Oscillation & 167 & 54.6 & 182 & 59.5 \\
\hline Consistency & 139 & 45.4 & 124 & 40.5 \\
\hline Mean \pm SD & \multicolumn{2}{|c|}{$4.42 \pm 1.90$} & \multicolumn{2}{|c|}{$4.19 \pm 2.00$} \\
\hline \multicolumn{5}{|l|}{ Rejection - acceptance } \\
\hline Rejection & 128 & 41.8 & 119 & 38.9 \\
\hline Acceptance & 178 & 58.2 & 187 & 61.1 \\
\hline Mean \pm SD & \multicolumn{2}{|c|}{$4.93 \pm 2.04$} & \multicolumn{2}{|c|}{$5.20 \pm 1.99$} \\
\hline \multicolumn{5}{|l|}{ Discrimination - equality } \\
\hline Discrimination & 206 & 67.3 & 215 & $\mathbf{7 0 . 3}$ \\
\hline Equality & 100 & 32.7 & 91 & 29.7 \\
\hline Mean \pm SD & \multicolumn{2}{|c|}{$3.67 \pm 1.97$} & \multicolumn{2}{|c|}{$3.67 \pm 1.98$} \\
\hline \multicolumn{5}{|l|}{ Total parenting style scale score } \\
\hline Higher level & 100 & 32.7 & 115 & 37.6 \\
\hline Lower level & 206 & 67.3 & 191 & 62.4 \\
\hline Mean \pm SD & \multicolumn{2}{|c|}{$17.67 \pm 5.18$} & \multicolumn{2}{|c|}{$18.16 \pm 5.27$} \\
\hline
\end{tabular}


Table (4): Frequency distribution of adolescents' self-compassion, bullying behavior and psychological resilience $(\mathrm{no}=306)$.

\begin{tabular}{|c|c|c|}
\hline & $N=(306)$ & $\%$ \\
\hline \multicolumn{3}{|l|}{ The self-compassion } \\
\hline Self-kindness & 5.95 & 2.51 \\
\hline Self-judgement & 6.54 & 2.35 \\
\hline Common humanity & 4.80 & 2.80 \\
\hline Isolation & 5.10 & 3.03 \\
\hline Mindfulness & 5.82 & 3.17 \\
\hline Over-identified & 6.12 & 2.55 \\
\hline Self-kindness & 5.95 & 2.51 \\
\hline Higher self-compassion & 236 & 77.1 \\
\hline Lower self-compassion & 70 & 22.9 \\
\hline Mean \pm SD & \multicolumn{2}{|c|}{$34.35 \pm 6.89$} \\
\hline \multicolumn{3}{|l|}{ Total violence/ bullying scale } \\
\hline Higher violence/ bullying & 84 & 27.5 \\
\hline Lower violence/ bullying & 222 & 72.5 \\
\hline Mean \pm SD & \multicolumn{2}{|c|}{$11.96 \pm 7.15$} \\
\hline \multicolumn{3}{|c|}{ Total psychological resilience scale } \\
\hline Higher degree of resilience & 305 & 99.7 \\
\hline low degree of resilience & 1 & 0.3 \\
\hline Mean \pm SD & \multicolumn{2}{|c|}{$94.25 \pm 11.36$} \\
\hline
\end{tabular}


Table (5): Bivariate correlational matrix of key study variables (parenting style, self-compassion, psychological resilience, and bullying behaviors) (no.=306).

\begin{tabular}{|c|c|c|c|c|c|c|c|c|c|c|}
\hline \multirow{2}{*}{ Key study variables } & \multicolumn{10}{|c|}{ Parenting style } \\
\hline & FDIS & FOCS & FRAS & FDES & FTPS & MDIS & MOCS & MRAS & MDES & MTPS \\
\hline Total self-compassion & $0.425 * *$ & -0.025 & $0.239 * *$ & $-0.175^{* *}$ & $0.176^{* *}$ & $0.227 * *$ & 0.070 & -0.026 & -0.030 & 0.085 \\
\hline Self-kindness & $0.237 * *$ & -0.025 & $0.127 *$ & $-0.125^{*}$ & 0.082 & $0.151 * *$ & -0.043 & 0.041 & -0.004 & 0.050 \\
\hline Self-judgement & -0.002 & -0.188 & 0.015 & $-0.243 * *$ & $-0.157 * *$ & -0.004 & -0.083 & -0.025 & $-0.192 * *$ & $-0.115^{*}$ \\
\hline Common humanity & $0.269 * *$ & 0.076 & $0.023 * *$ & 0.039 & $0.235 * *$ & $0.177 * *$ & $0.127 *$ & 0.103 & $0.175^{* *}$ & $0.215^{* *}$ \\
\hline Isolation & $0.218 * *$ & 0.093 & 0.089 & $0.186^{* *}$ & $0.221 * *$ & 0.018 & 0.062 & $-0.137^{*}$ & $0.160 * *$ & 0.038 \\
\hline Mindfulness & $0.191 * *$ & -0.062 & -0.035 & $-0.351 * *$ & -0.099 & $0.251 * *$ & 0.023 & 0.010 & $-0.298 * *$ & -0.12 \\
\hline Over-identified & $0.125^{*}$ & 0.013 & $0.186^{* *}$ & 0.047 & $0.142^{*}$ & -0.061 & 0.068 & -0.050 & 0.088 & 0.019 \\
\hline Total bullying & -0.093 & $0.214 * *$ & -0.080 & $0.355^{* *}$ & $0.148 * *$ & $-0.158 * *$ & 0.022 & $-0.188 * *$ & $0.215^{* *}$ & -0.037 \\
\hline Verbal bullying/violence & -0.097 & $0.121 *$ & $-0.135^{*}$ & $0.253^{* *}$ & 0.052 & $-0.207^{* *}$ & -0.015 & $-0.221 * *$ & 0.098 & $-0.125^{*}$ \\
\hline Physical bullying/violence & -0.077 & $0.276^{* *}$ & -0.015 & $0.407 * *$ & $0.222 * *$ & -0.088 & 0.055 & $-0.130 *$ & $0.301 * *$ & 0.054 \\
\hline Total psychological resilience & -0.010 & 0.044 & $0.163 * *$ & $-0.195^{* *}$ & 0.003 & 0.087 & 0.110 & $0.246^{* *}$ & $-0.193 * *$ & 0.093 \\
\hline Social support & -0.013 & 0.109 & $0.143^{*}$ & -0.105 & 0.052 & 0.100 & $0.161 * *$ & $0.280 * *$ & $-0.148 * *$ & $0.146^{*}$ \\
\hline Personal Efficiency/ capabilities & 0.039 & 0.025 & $0.184 * *$ & $-0.237 * *$ & 0.006 & 0.056 & 0.083 & $0.175^{* *}$ & $-0.195 * *$ & 0.044 \\
\hline Religious and value structure & $-0.133^{*}$ & -0.077 & 0.002 & -0.085 & -0.109 & 0.071 & -0.016 & $0.153 * *$ & -0.104 & 0.038 \\
\hline
\end{tabular}

FDIS:Fatherdependency- independency subscale, FOCS: Father oscillation - consistency subscale, FRAS: Father rejection - acceptance subscale, FDES: Father discrimination - equality subscale, FTPS: Father total parenting scale, MDIS:Motherdependency- independency subscale, MOCS: Mother oscillation - consistency subscale, MRAS: Mother rejection - acceptance subscale, MDES: Mother discrimination - equality subscale, MTPS: Mother total parenting scale, ${ }^{* *}$ Correlation is significant at the 0.01 level (2-tailed), *Correlation is significant at the 0.05 level (2-tailed). 
Table (6): Bivariate correlation of the parenting style, self-compassion, bullying, psychological resilience and adolescent's sociodemographic characteristics (no.= 306).

\begin{tabular}{|c|c|c|c|c|c|c|c|c|c|c|}
\hline \multirow{3}{*}{ Parenting style } & \multicolumn{10}{|c|}{ Adolescent's characteristics $\mathrm{No}=306$} \\
\hline & \multicolumn{2}{|c|}{ Age } & \multicolumn{2}{|c|}{ Sibling arrangement } & \multicolumn{2}{|c|}{ Housing } & \multicolumn{2}{|c|}{ Family size } & \multicolumn{2}{|c|}{ Residence } \\
\hline & $\mathbf{R}$ & $\mathbf{P}$ & $\mathbf{R}$ & $\mathbf{P}$ & $\mathbf{R}$ & $\mathbf{P}$ & $\mathbf{r}$ & $\mathbf{P}$ & $\mathbf{r}$ & $\mathbf{P}$ \\
\hline \multicolumn{11}{|l|}{ Mother parenting style } \\
\hline Dependency- independency & $0.179 * *$ & 0.002 & $0.190 * *$ & 0.001 & $-0.118 *$ & 0.039 & $0.322 * *$ & 0.000 & -0.016 & 0.785 \\
\hline Oscillation - consistency & -0.019 & 0.736 & $0.203 * *$ & 0.000 & -0.022 & 0.703 & $0.158 * *$ & 0.006 & 0.032 & 0.581 \\
\hline Rejection - acceptance & $0.155 * *$ & 0.007 & $0.0137 *$ & 0.017 & 0.015 & 0.795 & $0.232 * *$ & 0.000 & -0.065 & 0.259 \\
\hline Discrimination - equality & -0.217 & 0.000 & -0.067 & 0.244 & $0.114^{*}$ & 0.046 & 0.089 & 0.120 & -0.041 & 0.471 \\
\hline Total parenting style & 0.032 & 0.575 & $0.170 * *$ & 0.003 & -0.001 & 0.982 & $0.294 * *$ & 0.000 & -0.033 & 0.560 \\
\hline \multicolumn{11}{|l|}{ Father parenting style } \\
\hline Dependency- independency & $0.114 *$ & 0.046 & $0.197 * *$ & 0.001 & 0.003 & 0.962 & $0.147 *$ & 0.01 & 0.050 & 0.386 \\
\hline Oscillation - consistency & -0.069 & 0.231 & $0.213 * *$ & 0.000 & 0.037 & 0.518 & 0.099 & 0.084 & 0.019 & 0.745 \\
\hline Rejection - acceptance & 0.050 & 0.386 & $0.128^{*}$ & 0.025 & 0.096 & 0.093 & $0.157 * *$ & 0.006 & -0.047 & 0.408 \\
\hline Discrimination - equality & $-0.206 * *$ & 0.000 & $-0.155^{* *}$ & 0.006 & $0.138^{*}$ & 0.016 & 0.039 & 0.501 & -0.042 & 0.469 \\
\hline Total parenting style & -0.042 & 0.468 & $0.143^{*}$ & 0.012 & 0.105 & 0.067 & $0.167 * *$ & 0.003 & -0.046 & 0.422 \\
\hline
\end{tabular}




\begin{tabular}{|c|c|c|c|c|c|c|c|c|c|c|}
\hline Total self-compassion & $0.215^{* *}$ & 0.000 & $0.194 * *$ & 0.001 & -0.097 & 0.089 & $0.172 * *$ & 0.002 & -0.001 & 0.984 \\
\hline Self-kindness & $0.276^{* *}$ & 0.000 & -.109 & 0.056 & $-0.159 * *$ & 0.005 & $0.304 * *$ & 0.000 & -0.095 & 0.098 \\
\hline Self-judgement & 0.230 & 0.000 & 0.042 & 0.462 & -0.110 & 0.054 & 0.004 & 0.947 & 0.068 & 0.236 \\
\hline Common humanity & -0.059 & 0.300 & $0.257 * *$ & 0.000 & 0.000 & 0.999 & $0.128 *$ & 0.026 & -0.047 & 0.411 \\
\hline Isolation & $-0.161 * *$ & 0.005 & 0.60 & 0.293 & 0.077 & 0.177 & $-0.158 * *$ & 0.005 & 0.082 & 0.153 \\
\hline Mindfulness & $0.433 * *$ & 0.000 & -0.007 & 0.910 & $-0.188^{* *}$ & 0.001 & $0.328 * *$ & 0.000 & -0.053 & 0.351 \\
\hline Over-identified & $-0.185^{* *}$ & 0.001 & $0.247 * *$ & 0.000 & $0.137 *$ & 0.017 & $-0.196 * *$ & 0.001 & 0.048 & 0.400 \\
\hline Total violence / bullying & $-0.373 * *$ & 0.000 & -0.100 & 0.079 & 0.078 & 0.176 & $-0.228 * *$ & 0.000 & $-0.184 * *$ & 0.001 \\
\hline Physical bullying/violence & $-0.359 * *$ & 0.000 & $-0.119 *$ & 0.038 & 0.075 & 0.188 & $-0.130 *$ & 0.023 & $-0.161 * *$ & 0.005 \\
\hline Verbal bullying/violence & $-0.336^{* *}$ & 0.000 & -0.068 & 0.234 & 0.069 & 0.229 & $-0.296 * *$ & 0.000 & $-0.183^{* *}$ & 0.001 \\
\hline Total psychological resilience & $0.412 * *$ & 0.000 & -0.068 & 0.235 & -0.006 & 0.922 & 0.072 & 0.208 & -0.056 & 0.333 \\
\hline Social support & $0.450 * *$ & 0.000 & 0.047 & 0.413 & -0.008 & 0.885 & $0.133^{*}$ & 0.02 & $-0.152 * *$ & 0.008 \\
\hline Personal Efficiency/ capabilities & $0.283 * *$ & 0.000 & -0.089 & 0.119 & -0.028 & 0.622 & 0.022 & 0.696 & -0.002 & 0.970 \\
\hline
\end{tabular}

***orrelation is significant at the 0.01 level (2-tailed), *Correlation is significant at the 0.05 level (2-tailed 
Table (7): Results of multiple linear regressions for predicting father parenting style based on self-compassion, psychological resilience, and bullying behavior.

\begin{tabular}{|l|l|c|c|c|}
\hline $\begin{array}{c}\text { Criterion } \\
\text { (dependent)Variable }\end{array}$ & \multicolumn{1}{|c|}{ Predictor Variables } & $\begin{array}{c}\text { Standardized } \\
\text { coefficient } \\
\text { Beta }\end{array}$ & T & P-value \\
\hline \multirow{4}{*}{ Father Parenting style } & Model 1 Constant & & -0.640 & 0.523 \\
\cline { 2 - 5 } & Psychological resilience & -0.011 & -0.272 & 0.786 \\
\cline { 2 - 5 } & Mitigating bullying & 0.231 & 5.642 & 0.000 \\
\cline { 2 - 5 } & Mother parenting style & 0.708 & 18.65 & 0.000 \\
\cline { 2 - 6 } & Melcompassion & & & \\
\hline
\end{tabular}

F: ANOVA, Dependent Variable: Total Father parenting style Predictors: (Constant), Total Resiliency, Total Self Compassion, Total Mother parenting style, Total bullying, $(*)$ statistically significant at $\mathrm{p} \leq 0.05$ 
Table (8): Results of multiple linear regressions for predicting mother parenting style based on self-compassion, psychological resilience, and bullying behaviors.

\begin{tabular}{|l|l|l|l|l|}
\hline $\begin{array}{l}\text { Criterion } \\
\text { (dependent)Variable }\end{array}$ & Predictor Variables & $\begin{array}{l}\text { Standardized } \\
\text { coefficient } \\
\text { Beta }\end{array}$ & $\mathbf{T}$ & $\begin{array}{l}\text { P- } \\
\text { value }\end{array}$ \\
\hline $\begin{array}{l}\text { Mother Parenting } \\
\text { style }\end{array}$ & Model 2 Constant & & 2.82 & 0.005 \\
\cline { 2 - 6 } & Self-compassion & -0.103 & -2.43 & 0.015 \\
\cline { 2 - 6 } & psychological resilience & 0.052 & 1.28 & 0.201 \\
\cline { 2 - 6 } & Bullyingbehaviors & -0.169 & -3.881 & 0.000 \\
\cline { 2 - 6 } & Father parenting style & 0.757 & 18.652 & 0.000 \\
\hline
\end{tabular}

F: ANOVA, Dependent Variable: Total mother parenting style Predictors: (Constant), Total Resiliency, Total Self Compassion, Total father parenting style, Total bullying, (*) Statistically significant at $\mathrm{p} \leq 0.05$ 


\section{Discussion:}

Parenting style influences all phases of development and life style of adolescents. Recent literatures have got huge attention on this, parenting style constitute amyriad of attitudes and Pttern of behaviors through which parental authority is conveyed to the adolescent across avariety of sittings and situations. Researchs on adolescents found that authoritarian and harsh parental styles are closely related to psychological disturbance as lack of compassion toward self and decreased psychological resilience. Moreover, authoritarian parenting is positively associated to bully victim experiences at school, while authoritative parenting is negatively associative to the same variables (Georgiou, Ioannou \& Stavrinides, 2016) ${ }^{(28)}$. Contrary to reports that indicated that authoritarian parenting has negative influence, some researchers found that the authoritarian parenting style among Aferican Americans is associated with assertiveness and independence among girls with high risk environment (Dwairy\& Archoui, 2006) ${ }^{(29)}$. Hence, the overall aim of the current study was to investigate perceived parenting style, selfcompassion, and resiliency and mitigating bullying behavior among early adolescents.
The present study found that most parents were secondary educated. Almost all fathers and less than half of mothers were working.

Regarding parenting style, the results revealed that perceived parenting style by adolescents was very low with a mean of less than 20 scores. That was explained in lack of consistency in reward and punishment, lack of equality and increased discrimination between siblings with a mean of less than 5 scores.The finding disagree with Dwairy\&Menshar, $\mathbf{( 2 0 0 6 )}^{(\mathbf{3 0})}$, which revealed that authoritarian parenting style (lack of warmth and increased control or dependence) was prevalent in the upbringing of adolescent boys, while the authoritative style was more often used in the parenting of adolescent girls in a study made in rural village of Egypt.

Also, about two thirds of mothers and half of fathers accepted their adolescents' behavior, and about two thirds of mothers allowed their adolescents to be independent (permissive and neglected). This finding agrees with a study made on early adolescents by Chitra, (2016) ${ }^{(31)}$, which revealed that neglectful parenting was adopted by mother's one and half percent more than that of father's. 
However, the result disagrees with research by Mayuri \& Divya, (2015) ${ }^{(32)}$, which found that slightly more than half of rural adolescents' mothers were authoritarian. Furthermore, this disagree with a study made on Arab parenting style, the authoritarian mean score was higher among males (Dwairy \&Menshar, 2006) ${ }^{(30)}$.

Regarding adolescents self-compassion, the findings showed moderate mean level of self-compassion (SC) among studied adolescents. Specifically, in selfassessment and over identified subscales. This result agrees in one part with what Liem et al.,(2010) ${ }^{(33)}$ stated that adolescents who have parents accepting them exhibit positive self development and greater mastery across academic and social domains. However the result generally disagreed with a research made by Batool $\mathbf{( 2 0 1 3 )}^{(\mathbf{3 4})}$, which found that selfcompassion was positively correlated with the authoritative (accepting and controlling) parenting style. From the researcher's point of view, the results could be rationalized as perceived maternal acceptance plays a role for adolescents to develop SC, which minimizes the likelihood of psychological distress. This can be seen in the current study as total self-compassion is significantly negatively correlated with the mother-rejection parenting style, with $\mathrm{p}=-0,026$. Hence that agrees with Hall (2015) ${ }^{(\mathbf{3 5})}$, who revealed that adolescents may model their behavior in the way their mother treats them.

Rrgarding the bullying behavior the results of this study found that there was no significant pattern of bullying among the study group, as the mean of bullying was very low compared to non-bullying behaviour, and this disagreed with what Sarwar,(2016) $)^{(36)}$ stated that numerous studies have explained that school harassment is a common problem in elementary and secondary schools that affects up to half of children and adolescents. More over, the result disagree with a study made on Nigerian adolescents by Efobi\&Nwokolo,(2014) ${ }^{(19)}$, which reported that authoritative parenting style was more common among parents than other methods of parenting and the study showed a moderate tendency to bullying among adolescents. From the researcher's point of view, the result could be taken into account the nature of rural areas, since most of the samples studied are rural representing nearly all the sample size. However, a recent study conducted by Galal et al., (2019) ${ }^{(22)}$ revealed that there was a markedly high prevalence of 
bullying, more than three quadrant among adolescent rural school students.

The decrease in the level of bullying behavior could be related to the high resilience rate of the samples studied, which represent nearly all of the sample size, taking into account the higher religious faith of the students. The teachings of the Quran invite individuals to patience and a reasonable response to social conflicts and problems. It's because if a person doesn't react quickly, he or she will undergo less stress. As recommended in Baghareh (verse 45), "Seek assistance from prayer and patience [and gain strength from patience, control over lusts, and attention to God]; this is difficult for obedient believers" (Mohammadinia, Yaghoobi \& Kolahdouzan, 2012) ${ }^{(37) .}$

In relation to psychological resilience the finding revealed that adolescents in the study had higher psychological resilience than expected, this disagree with a Nigerian study revealed that competent parenting style and socio-economic resources increased mental health resilience in adolescents (Obimakinde, Omigbodun \&Adedokun, 2019) ${ }^{(38)}$. In addition to that, the study showed no significant correlation between total father parenting style and adolescent selfreported psychological resilience, and no correlation between total mother parenting style and adolescent psychological resilience. This result disagree with a study made on a university students revealed that acceptance-involvemen style was significant positive predictor of the resilience(Zakeri etal., 2010) ${ }^{(39)}$.

Theses findings could be related to other factors as type of study (Quran science) could be a major factor in increasing psychological resilience between siblings. Memorization of the Quran can affect internal factors (physical, emotional, motivational, behavioral and cognitive) and improve the mental health of individuals and contribute to the management of daily stress (Taghiabad, Ahrari \& Garai, 2015) ${ }^{(40)}$.

Regarding the relationship between parenting style and self-compassion, psychological resilience and bullying behaviour, the study found that father parenting style as perceived by adolescents was correlated with the self-compassion and bullying behavior of his adolescent. This means that the father parenting style reduces the behavior of adolescents who are bullied. This is consistent with a study conducted by Usman (2013) ${ }^{(\mathbf{4 1 )}}$, which found that bullies usually come from lowrelationship families, little warmth, absent fathers, authoritarian parents. and this 
contradicts the present study, as more than half of the fathers accept their adolescents and treat them with warmth and love and allow their adolescents to be independent, which could explain the decline in the pattern of bullying behaviour.

In contrast, however, we can see a lack of consistency and discrimination in the parenting style. From a researcher's point of view, this contradiction in feeling and behavior towards our adolescents is normal, as we are all human beings, and we are discussing the problem from a teenage point of view, so that they can feel discrimination between themselves and their sisters and brothers, this means that there are other factors that have mediation effects, with the control locus being a full mediator in the relationship between parenting style and victim-induced experience at school (Georgiou, et al., 2016) ${ }^{(28)}$.

Total bullying behavior was strongly negatively correlated with the age of the students. This result disagree with Badarna (2016) ${ }^{(\mathbf{4 2})}$ results, which showed that bullying behavior does not vary according to age, while Makary \& Daniel, (2016) $^{(\mathbf{4 3})}$ stated that the delinquency increases with old age, and the bullying appears in an early stage to develop gradually up to delinquency. Almost all of the study sample living with both father and mother and most of them has family members ranging from 4 to 7 members.Moreover, table 6 showed a strongly positive association between mother-father parenting style and family size with highly statistically significant difference. This means that the low parenting style is common in the low size family. However, this is not in agreement with the research done by Theresya, Latifah \& Hernawati (2018) ${ }^{(44)}$, which stated that the permissive parenting style was negatively correlated with the family size.

Inaddition to that, the birth order was significantly correlated with the parents' independence and permissive behavior as close to half of the sample were the oldest among siblings. This finding was in line with Dwairy \&Menshar $(\mathbf{2 0 0 6})^{(\mathbf{3 0})}$, who reported that firstborn adolescents had permissive parenting at higher rates than other adolescents.

Finally total self compassion, bullying behaviour and father parenting style can predict mother parenting style with highly significant difference. Also,self compassion, bullying behaviour and mother parenting style can predict father parenting style with highly statistically significant difference for all. This agrees 
with a research made by Biswas and Sharma (2019) ${ }^{(45)}$, that maternal parenting styles often have the greatest effect on developing children. Hence, it can be concluded that mothers and fathers play somewhat different roles in context of parenting and may have to parent and behave differently than each other. As the adolescent naturally discriminates that the female-gendered parent is for nurturance and support and that the male-gendered parent as a playmate, thus it is important to recognize such behaviors and prepare to respond to them accordingly,based on their respective genders, in order to be the best attuned to their child's needs.

\section{Conclusion:}

The parenting pattern has a great effect on the adolescents, , on their behavior and psychological state, taking into account parental age, educational level, and occupation, family size, children's age and sibiling arrangement, as well as living in an urban or rural environment. However, the results of the study show a lower level of parenting despite the fact that early adolescents have a good sense of selfcompassion, excellent psychological resilience and low levels of bullying. In addition to that, it can be noticed that adolescent's self-compassion, psychological resilience, bullying behaviour and fathers' parenting style is a predictors of mothers parenting' style and vice versa.

\section{Recommendations:}

- Application of the study on a larger and more diverse samples of adolescents

- It would be advantageous to collect data directly from parents in regard to their parenting style

- The school administration should invite the parents and conduct interviews with them to consider the method of parenting in the event of psychological problems or bullying of their children towards others.

- The school administration should activating the role of social or psychological specialist to dealing with bullied students or those with psychological disabilities

- Activating the role of academic guidance in the school to follow and identify student's social and psychological and behavioral problems

- Activating the sports clubs and extracurricular activities so that it is a breathing space for students to mitigating bullying and enhance psychological resilience and self compassion

- Further research should highlight the relationship between religiosity and 
parenting style, student selfcompassion, psychological resilience, and bullying behaviors.

- Further research should highlight the parenting practices and children developmental issues and psychological adjustment.

\section{Conflict of interest}

We have no conflict of interest to declare

\section{References:}

1. Bi, X., Yang, Y., Li, H., Wang, M., Zhang,W., \&Deater-Deckard, K.. Parenting styles and parent adolescent relationshup:the mediating roles of behavioral authority.Fron.psychol, 2018;13.

2. Pramudyani, A.V..The Effect of Parenting Styles for Children's Behaviour on Using Gadget at Revolution Industry, Jurnal Pendidikan Anak Usia Dini,2021; 5(1) 51-9.

3. Branje, S.. Development of ParentAdolescent Relationships: Conflict Interactions as a Mechanism of Change, Child development perspectives, 2018;12( 3): 171-76.

4. Vega, A.D., Hapidin \& Karnadi.. Pengaruh Pola Asuh dan Kekerasan Verbal terhadap Kepercayaan Diri, Jurnal Pendidikan Anak Usia Dini, 2019;3(2): 433-39.
5. Smetana, J.G. Current research on parenting styles, dimensions, and beliefs, Current Opinion in Psychology.2017; 15(165 ):19-25.

6. Hasanah, N., \& Sugito. Analisis Pola Asuh Orang Tua terhadap Keterlambatan Bicara pada Anak Usia Dini, Jurnal Pendidikan Anak Usia Dini, 2020;4(2): 913-22.

7. Jahja, Y. Psikologi Perkembangan (Keempat). Prenadamedia Group. Journal of Community and Applied Social Psychology. 2015; (10): 17-31.

8. Paler, Juvert N., Batiller, Kenneth B., \& Valiente, L. Parenting Style and Task Performance of Students. International Journal of Scientific and Research Publications. 2019;9(1) :1-6.

9. Jafari, B.. Ten steps toward improving creativity. Available at: http://www.aftabir.com/articles/view/a pplied_sciences.2016.

10. Liu, Y. \& Merritt, D.H. Examining the association between parenting and childhood depression among Chinese children and adolescents: A systematic literature review. Child. Youth Serv. 2018; (88):316-32.

11. Moilanen, K.L., Rasmussen, K.E., Padilla-Walker L.M. Bidirectional associations between self-regulation 
and parenting styles in adolescence. $\mathrm{J}$

Res Adolesc. 2015; (25):246-62.

12. Mead, G.H. Mind, Self, and Society from the Standpoint of Social Behaviorist. University of Chicago Press: Chicago. 1934.

13. Ahmed, N., \& Bhutto, Z.,H.Relationship between Parenting Styles and Self Compassion in Young Adults. Pakistan Journal of Psychological Research. 2016; 31(2): 441-51.

14. Germer, C. K., \& Neff, K. D. Teaching the Mindful SelfCompassion program: A guide for professionals. New York: Guilford Press. 2018.

15. Ann S., Masten J. J., Janette E. C., Hinz, H.E., \&Obradović. J. Academic Risk and Resilience in the Context of Homelessness. Child development prespectives.2014;8(4).

16. Cheng, Y., Wang, F., Wen. J.,\& Shi. Y. Risk factors of Post-Traumatic Stress Disorder (PTSD) after Wenchuan earthquake: a case control study. PLoS ONE. 2014; 9(5):e96644.

17. Doll. B., Brehm, K., and Steven Zucker, S.. Resilient Classrooms: Creating Healthy Environments for Learning, 2nd ed., Guilford Publications press. 2014; 1-6.
18. Mobarki, A.A., Morsi, N.M., \& Hamouda, G., Teachers' Perception Regarding Bullying. International Journal of Novel Research in Healthcare and Nursing 2020;7 (1), 742-52 Available at: www.novelty journals.com .Novelty Journals.

19. Efobi, A., \& Nwokolo. C. Relationship between Parenting Styles and Tendency to Bullying Behaviour among Adolescents. Journal of Education \& Human Development. 2014;3(1):507-521.

www.aripd.org/jehd.

20. Rodriguez. T. "Harsh Parents Raise Bullies-and Their Victims" in SA Mind 27 , 5 , 14.doi:10.1038/scientificamericanmind. 2016;0916-14a.

21. Wiedemann1, D., Vogel, C., Voss, M., Nusseck, \& Hoyer, J. The role of retrospectively perceived parenting style and adult attachment behaviour in music performance anxiety. Preprint [PsychArXiv Available online at https://psyarxiv.com/k5npv2018 .

22. Galal. Y., Emadeldin. M., \& Mwafy. M. Prevalence and correlates of bullying and victimization among school students in rural Egypt. Journal 
of the Egyptian Public Health Association.2019;94, (18).

23. Arkin, H. Statistical Sampling for Auditors, NY: PriceWaterhouse \& Co., 1960.

24. Abdel Aziz, E. Affiliation with the family and its relationship to methods of social upbringing, unpublished doctoral dissertation, Faculty of Arts, Ain Shams University; 1987.

25. Raes, F., Pommier, E., Neff, K.D., and Gucht, D.V. Construction and factorial validation of a short form of the selfcompassion scale. Clinical Psychology and Psychotherapy. 2010;18, 250-255.

26. Jamal Al-Din, I.I. Bullying/Violence as percieved by Adolescents 15-16 Years, Master Thesis, Ain Shams University, Institute of Higher Studies for Childhood, Cairo, 2008.

27. Jew, C., Green, K., and Kroger,J.Developmant and validation of measure of resiliencey.Journal of measurment and evaluation in counselling and development. 1999;32(2): 75-90.

28. Georgiou, S. N., Ioannou, M., \& Stavrinides, P. Parenting styles and bullying at school: The mediating role of locus of control Journal International Journal of School \& Educational Psycholog. 2016; 5 (4).
29. Dwairy, M., \& Achoui. M. Introduction to Three Cross-Regional Research Studies on Parenting Styles, Individuation, and Mental Health in Arab Societies. Psychology. 2006; $37(3)$.

30. Dwairy, M., \&Menshar, K.E. Parenting style and individuation and mental health of Egyptian adolescents. Journal of Adolescence. 2006; 29(1): 103-117.

31. Chitra., Sukumaran. A Perceived Impact of Parenting Style on SelfEsteem among Early Adolescents at Selected Schools, Ernakulam. International Journal of Nursing Education.2016;8(1) 185.

32. Mayuri, V. \& Divya, K. K.Parenting Styles as Perceived by Parents and Children Scientist, Project on Parenting Experiences: A Life Cycle Analysis of Urban and rural families ${ }^{\text {ee }}$ ICAR, 2015-17. At College of Home Science, Professor Jaishankar Telangana State Agricultural University, Saifabad, Hyderabad. 2Senior Research Fellow, Emeritus Scientist Project, 2015-17.

33. Liem.H., Emily Cohen Cavell \&Kara Lustig. The Influence of Authoritative Parenting during Adolescence on Depressive Symptoms in Young 
Adulthood: Examining the Mediating Roles of Self-Development and Peer Support. Journal of Genetic Psychology. 2010;171(1).

34. Batool, S. Lack of adequate parenting: A potential risk factor for aggression among adolescents. Pakistan Journal of Psychological Research.2013;28(2): 217-36.

35. Hall, J.I. An Examination into the Relationship between SelfCompassion and Parenting Styles. An Undergraduate Thesis Submitted in Partial Fulfillment of the Requirements for the Honors College and the Honors-in-Psychology Program College of Arts and Sciences East Tennessee State University. 2015.

36. Sarwar. S. Influence of Parenting Style on Children's Behaviour.Journal of Education and Educational Development. 2016;3 (2): 222249.DOI: 10.22555/joeed.v3i2.1036.

37. Mohammadinia, L., Yaghoobi. M., Kolahdouzan, A. Anxiety Management by Relaxation Approach: Quranic Verses. Health Information Management. 2012;8(8): 1225.

38. Obimakinde, A.M, Omigbodun, O., Adedokun, B., Parenting styles and socio-demographic dynamics associated with mental health of in- school adolescents in Ibadan, southwest Nigeria. Journal of Child and Adolescent Mental Health. 2019; 31(2) 109-24.

39. Zakeri, H., Jowkar.B., \& Razmjoee.M. Parenting styles and resilience. Procedia - Social and Behavioral Sciences. 2010;(5) :1067-70.

40. Taghiabad, B.A., Ahrari, S. \& Garai, Z., Mental Health and Stress-coping Strategies among Memorizers of Holy Quran, Health, Spirituality and Medical Ethics. 2015; 2(2) 15-21.

41. Usman, I. "Kepribadian, Komunikasi, Kelompok Teman Sebaya, Iklim Sekolah dan Perilaku Bullying." Journal Humanitas, 10,2013.

42. Badarna. L. Level of Bullying Behavior and its Relation to Gender and Age among Adolescents in AlNassera City. Research on Humanities and Social Sciences www.iiste.org ISSN (Paper) 2224-5766 ISSN (Online) 2225-0484 (Online). 2016;.6,

43. Makary, M. A., \& Daniel, M. Medical error - the third leading cause of death in the US. Bmj. 2016; 353(139).1-5

44. Theresya, J., Latifah, M., \& Hernawati, N., The Effect of Parenting Style, Self-Efficacy, and Self Regulated Learning on Adolescents' 
Academic Achievement. Journal of Child Development Studies. 2018; 03(01): 28-43.

45. Biswas, S., andSharma. P. Case report to Study the Gender-Wise Difference in Parenting Styles of Mother and Father. Scolarly journal of psychology and behavioral sciences. 2019;2 (5): 236-48. 